
\title{
25 Research Sourere \\ Exploring Mandarin Chinese Teacher's Knowledge Base in China and the US: A Comparative Case Study
}

Moi Mooi Lew ( $\sim$ moimooi.lew@wmich.edu )

Western Michigan University https://orcid.org/0000-0002-1569-4258

Liu Liu

Western Michigan University Homer Stryker MD School of Medicine

\section{Original article}

Keywords: Mandarin Chinese teachers, knowledge base, curricula inquiry, subject matter, procedural knowledge, contextual knowledge, comparative study

Posted Date: August 17th, 2020

DOI: https://doi.org/10.21203/rs.3.rs-58770/v1

License: (c) (i) This work is licensed under a Creative Commons Attribution 4.0 International License.

Read Full License 


\section{Abstract}

This study aimed to explore Mandarin Chinese teachers' knowledge base in two different sociocultural contexts by comparing graduate level's Teaching Chinese As a Foreign Language (TCFL) teacher education program curricula in China and the United States. The unit of analysis included four TCFL teacher education programs in both countries. The program curricula were analyzed based on three domains of knowledge, i.e., subject matter knowledge, procedural knowledge, and contextual knowledge. The comparative study results revealed that both countries focus on different domains of knowledge. China emphasis subject matters knowledge and the US focuses more on procedural knowledge. This study suggested that the TCFL teacher education program curricula in China should modify to focus more on the processes of Chinese second language teaching. The findings also asserted that the US's TCFL teacher education curricula should focus more on the Chinese language subject matter knowledge so that graduates possess in-depth content knowledge to handle students' misconceptions in second language acquisition. Mandarin Chinese teachers in both countries possess different domains of knowledge.

\section{Introduction}

\section{Research background and purposes}

In China, in the past 20 years, many Teaching Chinese as a Foreign Language (TCFL) teacher education programs have created and implemented to accommodate the increasing demands for certified Chinese language teachers (Cheng, 2015; Ke \& Li, 2011; Wang, Moloney \& Li, 2013). Particularly, TCFL teacher education programs at the graduate level had been emphasizing since 2006 due to shorter training periods (Zhu \& Han, 2006). A statistic in 2012 showed that 285 higher education institutes in China offering Master of Arts (MA) teacher education programs in TCFL with the program name "Master of Teaching Chinese to Speakers of Other Languages (MTCSOL) (Cheng, 2015; Wang, Moloney \& Li, 2013). In addition to MTCSOL, some China universities established a Master of Arts (MA) program in the field of 'linguistics and applied linguistics' with a sub-research area in TCFL. The MTCSOL and other TCFL's MA programs typically take two-three years to complete a total of 38-42 credit hours courses. Graduates from these programs are expected to possess substantial content knowledge of Chinese linguistics and cultures, skillful in teaching Chinese as second language pedagogy, and strong intercultural communication skills (Cheng, 2015). Due to the demands for Chinese teachers internationally, many graduates from TCFL teacher education programs have been hired by the Office of Chinese Language Council International (Hanban) to work for the Confucius Institutes outside of China to promote Chinese language and cultures globally (Cheng, 2015). This initiative has no doubt ease the demands for Mandarin Chinese teachers worldwide.

Comparatively, in the United States (US) context, some universities also offer a MA in teaching Chinese as a Second Language (MATCSL) program. Some MA programs arose within the department of applied linguistics or department of languages and literature (Crandall, 2000; Wang, Moloney \& Li, 2013). 
However, considering that language teaching should be an educational enterprise, not a linguistic one, a majority of the Chinese language teacher education programs were housed in the College of Education (e.g., Michigan State University, Western Michigan University, etc.). Some MATCSL programs were integrated with world language teacher education programs where the Chinese language is one of the concentrations (e.g., University of North Carolina Charlotte). As such, applicants were required to submit Chinese language proficiency test scores as a prerequisite admission criterion. Some programs required Chinese native speaker applicants with a superior level of Chinese speaking proficiency assessed by the ACTFL's Oral Proficiency Interview test. After enrolling in the language teacher education programs, the education department will equip intern teachers with procedural knowledge such as how to designing and implementing instructional activities, and how to manage classrooms, etc., and opportunities for developing teaching skills and dispositions (Crandall, 2000). Intern teachers are also required to conduct many professional field experiences in schools. The MATCSL programs typically require 30-40 credit hours to be completed within 1-2 years. Upon graduation, Chinese teacher candidates will earn a teaching certificate to become a certified Mandarin Chinese teacher in the US (Western Michigan University, 2020).

Both MTCSOL and MATCSL programs are university postgraduate teacher education programs that focus more on the integration of language teaching skills and pedagogical content knowledge. The programs assume that pre-service teachers have already mastered the subject matter knowledge at their undergraduate university level (Mattsson, Eilertsen, \& Rorrison, 2011, p.190). Unfortunately, being able to speak a language does not necessarily mean that they have a solid understanding of the literacy aspects of a language and skillful in second language teaching pedagogies (Lafayette, 1993; Orton, 2011; Senchuk, 1984). Besides, past studies showed that a significant number of Chinese teachers encountered difficulties in adapting their teaching approaches in the foreign language classrooms (Cheng, 2015; Liao, Yuan, \& Zhang, 2017; Wang \& Tian, 2013; Xu, 2012). For example, research conducted by Liao, Yuan, and Zhang (2017) noted that Chinese teachers encountered challenges in implementing effective world language instructional strategies in US classrooms.

From the policy perspective, according to the Council for the Accreditation of Educator Preparation (CAEP) Program Standards for the Preparation of Foreign Language Teachers (2015), Chinese teachers should demonstrate an understanding of the multiple content areas that comprise the field of Chinese as a foreign language study. They should also demonstrate an understanding of the interrelatedness of perspectives, products, and practices in the target cultures. Also, they should know the linguistic elements of the Chinese language system, and they can recognize the changing nature of language (CAEP Program Standards for the Preparation of Foreign Language Teachers, 2015). However, in reality, little is known if the MTCSOL and MATCSL graduates pose essential subject matter knowledge, procedural knowledge, and other domains of teacher knowledge needed to perform required teaching roles. Research on the Chinese teacher's knowledge base is still underrepresented within the Second Language Teacher Education (SLTE) literature (Dooley, Dangel, \& Farran, 2011). Hence, we embarked on this study to examine Chinese teachers' knowledge base in both China and the US context through a comparative curriculum inquiry. The comparative study findings will add literature to the field of Second Language 
Teacher Education (SLTE) by unpacking the conceptualization of Mandarin Chinese teachers' knowledge base which is needed to better serve their teaching responsibilities in a foreign language classroom.

Considering that China is the country with Chinese as its native language and has a long-established history of teaching Chinese as a foreign language teacher education programs and the US has a strong foundation in world languages teaching strategies, the primary goal of this study was to investigate Chinese teachers' knowledge base in two different sociocultural contexts. The investigation was carried out by analyzing the program curricula of selected Teaching Chinese as a Foreign Language teacher education programs (TCFLTE) in both countries. For the remaining parts of this paper, the term Teaching Chinese as a Second Language Teacher Education (TCSLTE) and TCFLTE is being used interchangeably. This study addressed three research questions as follow:

1. What domains of knowledge integrated into the curricula of Chinese language teacher education programs in China and the US?

2. What are the similarities and differences of TCSLTE program curricula in China and the US?

3. What domain of knowledge should be included in the TCSLTE program curricula in China and the US?

\section{Knowledge Base of Second Language Teacher Education Programs}

The knowledge base itself and all its components should be a central part of any teacher education program including language teacher education programs. Historically, the content of language teacher education was defined with two constituents: subject matter knowledge and pedagogical skills (Freeman, 1989). In this study, knowledge base refers to the expertise, understanding, awareness, knowledge, and skills that second language teachers need to possess to be effective teachers (Day, 1993; Freeman \& Johnson, 1998; Richards, 1998; Tedick, 2009). Second language teaching is complex compared to other subject matters in that the target language is both the medium of instruction and the object of learning. Conceptualizations vary as to what the "knowledge base" of second language teaching entails and how it is constituted (Faez, 2011). Most scholars would agree that being a native speaker does not guarantee he/she is a good teacher (Lafayette, 1993; Orton, 2011). It is also true that content knowledge does not translate automatically into pedagogical content knowledge. This section briefly discussed some influential knowledge base models in the field of SLTE that formed the theoretical foundation of this study.

In the late 80s, the literature showed that Shulman's model (1987) emerge as the most influential theoretical framework in describing the teacher's knowledge base. Shulman's (1987) model proposed that the teacher's knowledge base consists of six categories: content knowledge, general pedagogical knowledge, pedagogical content knowledge, curriculum knowledge, knowledge of the learner, and knowledge of educational goals and their philosophical bases (Barahona, 2014). More details, according to Shulman, content knowledge is the subject matter or what teachers teach. The general pedagogical knowledge refers to general pedagogical skils that the teacher needs to acquire to carry out the teaching 
activity. The pedagogical content knowledge relates specific pedagogical skills of how language should be taught (Golombek, 1998). Next, curricular knowledge is described as the teachers' knowledge of school curricular and how they make use of it during teaching and learning processes. The knowledge of the learner refers to knowledge about learners in various aspects such as physical, psychological, and cognitive characteristics. Finally, the knowledge of educational goals and their philosophical stance sees that teachers inquire about the educational system principles and social expectations as educators. Language teachers' knowledge base should include these six categories too.

In the 90s, Day (1993) argued that the SLTE program should include four categories of knowledge, i.e., content knowledge, pedagogical knowledge, pedagogical content knowledge, and support knowledge. In this paradigm, content knowledge refers to knowledge of the subject matter; pedagogic knowledge refers to knowledge of practices of teaching; pedagogic content knowledge refers to knowledge of teaching strategies for teaching the subject matter, and support knowledge refer to knowledge of fields/disciplines which influence language teaching such as linguistics and sociolinguistics (Faez, 2011). Day's framework emphasizes the role of the support knowledge as "the knowledge of the various disciplines that inform our approach to the teaching and learning languages; e.g., psycholinguistics, linguistics, second language acquisition, sociolinguistics, research methods" (Day, 1993, p. 4). However, Day's knowledge categories have not concerned about the role of the teacher as a learner and how they learn to teach (Nguyen, 2013). Next, both Roberts (1998) and Richards (1998) suggest six types of teacher knowledge. Roberts (1998) advocated that the knowledge base should include content knowledge, pedagogical content knowledge, general pedagogic knowledge, curricular knowledge, contextual knowledge, and process knowledge. Meanwhile, Richards (1998) suggested six domains of knowledge: theories of teaching, teaching skills, communication skills, subject matter knowledge, pedagogical reasoning and decision making, and contextual knowledge.

Following that, Freeman and Johnson (1998) proposed a reconceptualized knowledge base of SLTE that pays attention to the "activity of the teaching itself- who does it, where it is done, and how it is done" (Freeman \& Johnson, 1998, p. 405). They agreed that a knowledge base must consider three inter-related activities of teaching: the teacher-learner, the social context, and the pedagogical process (Freeman \& Johnson, 1998). This domain of knowledge also comprises the necessary socialization that teachers need to go through at the schools, and the pedagogical issues they faced during the teaching and learning process (Johnston \& Goettsch, 2000). Freeman and Johnson's model contributes to the improvements in the SLTE program. It is believed that a sociocultural perspective is crucial for the development of SLTE as it accounts for both the content and the process of SLTE (Nguyen, 2013). As little is known about Chinese teachers' knowledge base that needed to support students learning a second language in China and the US context, this curricular inquiry of TCFL teacher education programs should be relevant in the field of second language teacher education.

\section{TCFL Teachers' Knowledge Base}


The literature review indicated that language teachers' knowledge base generally can be grouped into three domains of knowledge which are subject matters knowledge, contextual knowledge, and procedural knowledge. As such, in this study, the curricula of TCSL teacher education programs in China and the US were reviewed to find out if courses offered in the programs equip Chinese teachers with these three domains of knowledge. Three domains of knowledge are discussed in this section.

\section{Subject Matter Knowledge}

Both Roberts (1998) and Richards (1998) suggested that teachers should possess in-depth subject matters knowledge to support students learning the languages. Subject matter knowledge is content knowledge or what teachers teach (Day, 1993; Johnson, 1999; Richards, 1998, Roberts, 1998; Shulman, 1987). In this case of Chinese language teaching, subject matter knowledge includes content knowledge of Chinese linguistics such as pinyin, syntax, morphology, and grammar (e.g. Kumaravadivelu, 2006b). Subject matter knowledge is of utmost important knowledge for language teachers and its crucial role has been advocated by many scholars. For example, Shulman (1987) noted that language teachers should have some content knowledge to enable teachers to relate the second language learning to learner's first language background. Similarly, Zeichner (2006) claimed that language teachers who lack content knowledge will contribute to the low quality of teaching. Teachers who do not have in-depth content knowledge tend to develop the lessons using textbooks and are not capable to deal with students' confusion in language learning (Zeichner, 2006, p.23). Literature in the field of SLTE warrants the need to include relevant subject matters knowledge in TCSLTE programs.

\section{Contextual Knowledge}

Both Roberts (1998) and Richards (1998) also suggested that teachers should possess contextual knowledge to support their teaching role. Context knowledge refers to knowledge about the classrooms, school, the institution, or the community where teaching and learning will take place (Johnson, 1999, p.24). Borg (2003) conceptualized contextual factors as "the social, psychological, and environmental realities of the school and the classroom" (p.94). This domain of knowledge comprises of knowledge about stakeholder's expectation, school culture, state curriculum standards, district and school policies, standardized tests, and teaching resources (Borg, 2003, p. 94). Besides, the contextual factors encompass governmental, markets, property rights, law, race, gender, religion, and disability (Grant \& Gillette, 2006, p.294). In a broader sense, teachers should pay attention to the sociocultural and institutional contexts when designing their lessons' content and making decisions on the pedagogy approaches. Inevitably, scholars advocate that SLTE should equip pre-service second language teachers with contextual knowledge before they begin teaching in schools.

\section{Procedural Knowledge}

Both Roberts (1998) and Richards (1998) advocated that teachers should possess procedural knowledge

to function efficiently in their day-to-day works. Procedures knowledge involves the knowledge of how to teach a language. The procedures include planning, presenting the content, using the teaching aids or 
resources, managing the classrooms, and assessing student learning. Shulman called it as pedagogical content knowledge (PCK). Meanwhile, Malderez and Wedell (2007) claimed that PCK is the most crucial knowledge that pre-service teachers should learn. It is pointless to just have subject matter and contextual knowledge but lack of knowledge on how to deliver the content to support student learning ( $p$. 24-25).

Some scholars claimed that procedural knowledge should include knowledge of how to assess student learning (Darling-Hammond, 2006; Intrator, 2006). Knowledge of assessment has two complementary forms: assessing the learners and self-assessment by language teachers. It is suggested that teachers acquire the skill of formative assessment to find out if the learning objectives of a particular lesson, topic, or skill are being met (Darling-Hammond, 2006). In this case, language teachers should have developed their understanding of how to continuously assess learners and also to use the assessment data as a reference for the improvement of their teaching practice during teacher preparation period (Intrator, 2006). As such, literature suggested that pre-service teachers need to be supported during their SLTE to develop a clear rationale and deeper understanding of the testing process as it forms an important aspect of their teaching. Procedural knowledge is essential for all pre-service second language teachers. To conclude, in this study, we claimed that Chinese language teachers' knowledge base should consist of three domains of knowledge, i.e., content knowledge, contextual knowledge, and procedural knowledge. All three categories of knowledge should be addressed by the curriculum developers when designing a TCSLTE program.

\section{Methods}

This project employed a qualitative research methodology to conduct a comparative case study on TCFL teacher education program curricula in China and the US. Both countries produce Chinese teachers teaching force and contextually, both countries exist significant cultural differences in terms of race, language, religion, and political system. Hence, the selection of countries of China and the United States when making a comparison is justified (Ellis \& Loughland, 2016). The comparative case study approach was exploratory in nature to discover the general underlying differences in the curriculum structures and their philosophical orientations to understand Chinese Mandarin teachers' knowledge base in both countries. A total of four master-level TCFL programs in different parts of China were selected as a unit of analysis. The universities were named as University A, B, C, and D. Similarly, four master level's TCFL teacher education curricula in the US's Midwest region was chosen to review in this comparative study. The universities were named as University $\mathrm{W}, \mathrm{X}, \mathrm{Y}$, and $\mathrm{Z}$.

In the first phrase, curriculum documents for MTCSOL in China and MATCSL in the US were first analyzed to examine the similarities and differences in the three domains of knowledge. Two types of documents were used as data in this study. The first type of documents was TCFL program teacher education curricula in China and the US, collected from the respective universities' websites and interview participants. The second type of documents was national standards curriculum shared by the interview participants. In the second phrase, four teacher educators from the eight universities were recruited to 
conduct a semi-structured interview to supplement curriculum document reviews. The interviews with teacher educators were conducted after the initial analysis of curriculum document had been completed. Each interview was between 30-40 minutes. The results of the initial document analysis were used to seek further clarification from the interview participants. The interview participants had provided some insights on the rationale of the TCSL teacher education programs curricula. Document analysis was used to analyze the two types of documents. For data analysis, the courses offered by each university in China and the US were examined carefully and coded to three domains of knowledge based on the literature review of knowledge base in the field of SLTE. Each domain of knowledge was calculated based on the credit hours for each domain of knowledge per total credit hours for each TCFL teacher education program. For instance, if three 6-point units are coded as contextual knowledge, the total credit points for that domain will be 42 points and the percentage is about 42.9 (i.e. 18 out of 42). Interview transcripts were transcribed and translated from Chinese to English. To ensure a better flow of discussion, excerpts from interview transcripts were not restricted to a verbatim translation. To ensure the trustworthiness of the interview data, the transcripts were then returned to respondents for member checking.

\section{Results}

This study aimed to conduct a comparative curricular inquiry of the master level's TCFL teacher education programs in China and the US. The curricula inquiry will reveal Chinese teachers' knowledge base in two different contexts.

\section{National TCFL Teacher Education Program Curriculum in China}

The curriculum document analysis revealed that in China, the national standards curriculum of MTCSOL was created by the International Chinese Education Master Program Curriculum Committee Board affiliates to China's Ministry of Higher Education in 2009. The minimum credit hours for this standardized curriculum was 38 . Table 1 below displays the program curriculum developed by the Curriculum Committee Board. More than $50 \%$ (20 out of 38 ) of the total credit hours were allocated for professional core courses. Procedural knowledge made up to 12 credit hours in total. About 6 credit hours were allocated for public essential courses which aimed to provide contextual knowledge to teacher candidates in China.

Table 1

Standardized MTCSOL Program Curriculum Structure 


\begin{tabular}{|ll|}
\hline Category & Credit Hours \\
\hline Public Essential Courses & 6 \\
\hline Core Courses & 12 \\
\hline Elective Core Courses (Linguistics, Cultures, Intercultural Communication, etc.) & 8 \\
\hline Experiential and Educational Learning & 4 \\
\hline Teaching Practices & 6 \\
\hline Thesis & 2 \\
\hline Total Credit & 38 \\
\hline
\end{tabular}

Table 2 presents an overview of the recommended MTCSOL program curriculum by the Curriculum Committee Board. Prior to analysis, the MTCSOL program curricula were categorized into three integrated domains of knowledge: subject matter, contextual, and procedural. More details, core courses, elective core courses, Chinese cultural, and intercultural communication equip teachers with substantial subject matter knowledge. Experiential learning courses, educational courses, teaching practices, and the graduate dissertation aimed to provide teacher candidates with procedural knowledge. Meanwhile, the goals of the public essential courses such as politics were to equip teacher candidates with contextualized knowledge. The allocation of credit hours to each domain of knowledge revealed the MTCSOL program's theoretical orientation that embraced by the Chinese scholars and educational policymakers in the field of teaching Chinese as a foreign language in China.

Table 2

Recommended MTCSOL Program Curriculum by the Curriculum Committee Board 
Public Essential

Politics ( 2 credits)

- Foreign Languages (4 credits)

Core Courses

Elective Core Courses

Including Chinese Cultures and Intercultural Communication
Teaching Chinese as a Second Language (4 credits)

- Second Language Acquisition (2 credits)

- $\quad$ Chinese Teaching Classes Abroad (2 credits)

- Chinese Culture and Communication (2 credits)

- Intercultural Communication (2 credits)

- Teaching Chinese language elements (2 credits)

- Errors analysis (2 credits)

- Chinese and foreign language contrast (2 credits)

- Curriculum design (2 credits)

- Modern language education technology (2 credits)

- Chinese textbooks and teaching resources $(2 \mathrm{cre})$

- History of Chinese thought

- Country and regional culture

- Etiquette and International Relations

- Sino-Foreign Cultural Exchange

Educational Courses \& Experiential Learning
- Psychology of Foreign Language Education

- Foreign primary and secondary school education

- Design and management of special subject teaching in foreign primary and secondary education

- International Promotion of Chinese

- Teaching Survey and Analysis (1 credit)

- Classroom Observation and Practice (1 credit)

- Teaching Test and Evaluation (1 credit) 


\section{Selected TCFL Teacher Education Program Curricula in China}

Table 3 showed a summary of four selected TCFL teacher education program structures in comparison with the national program structure of MTCSOL. As can be seen, all four universities have different program structures yet they all conform to the program standards guidelines set by the Curriculum Committee Board. All four universities maintained the core content of the curriculum designated by the International Chinese Education Master Program Curriculum Committee Board. Each university has included specific courses based on available resources and program needs.

Table 3

Summary of Courses Offered by Selected TCFL Teacher Education Programs in China

\begin{tabular}{|llllll|}
\hline Category & National & Uni. A & Uni. B & Uni. C & Uni. D \\
\hline Public Essential Courses & 6 & 8 & 7 & 6 & 6 \\
\hline Core Courses & 12 & 12 & 16 & 14 & 12 \\
\hline Elective Core Courses & 8 & 10 & 10 & 8 & 12 \\
\hline Experiential \& Educational Learning & 4 & 4 & 4 & 4 & 4 \\
\hline Teaching Practices & 6 & 6 & 6 & 6 & 6 \\
\hline Thesis & 2 & 2 & 5 & 10 & 2 \\
\hline Total Credits & 38 & 42 & 48 & 48 & 42 \\
\hline
\end{tabular}

Table 4

Subject Matters Knowledge Domain Courses and Total Allocated Credit Hours 


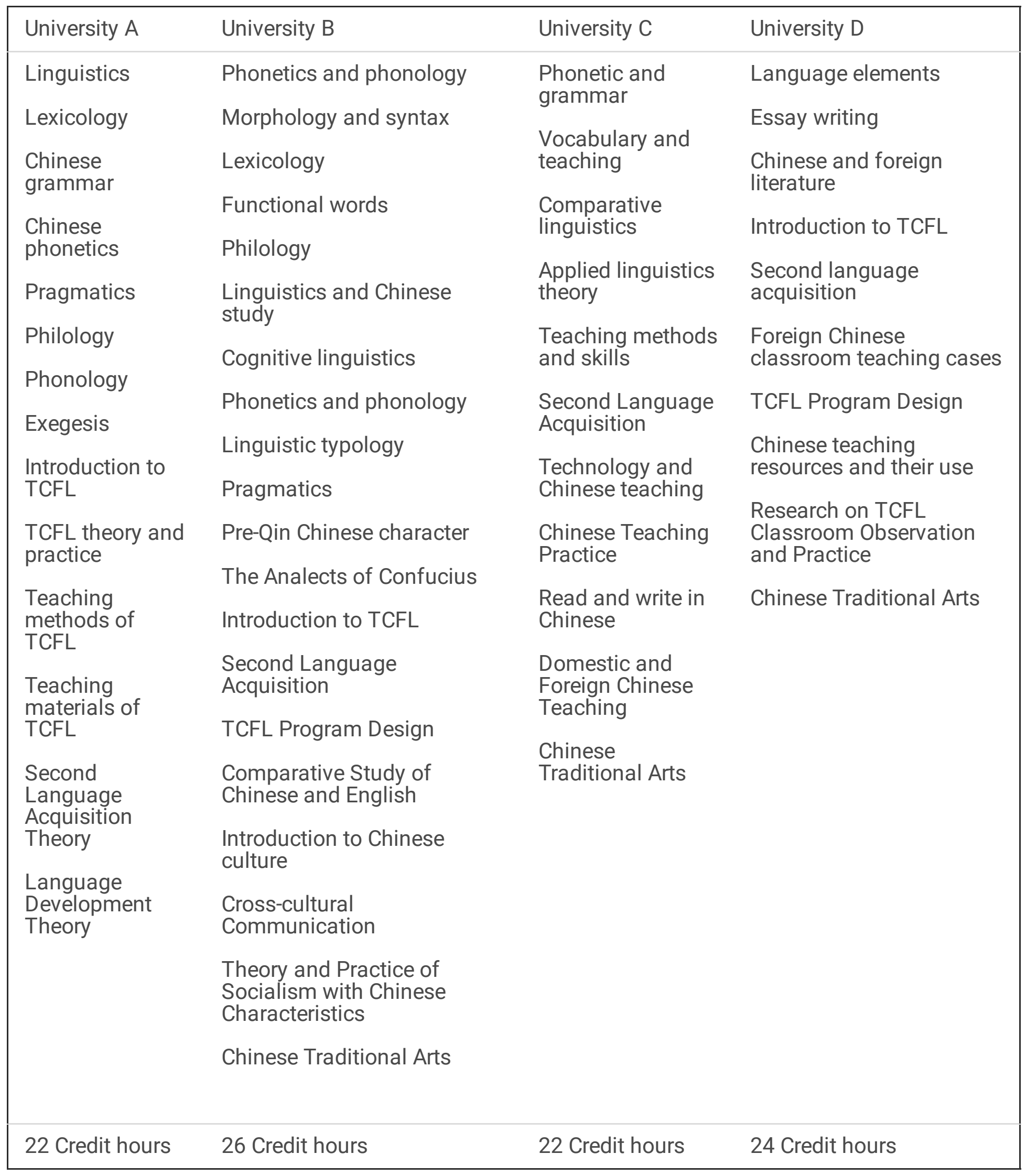

Table 4 above listed the courses offered by each university to prepare TCFL teachers with substantial subject matter knowledge to assume the role of a Chinese teacher both inside and outside of China. 
Based on the number of credit hours, there were some differences across the four universities. In comparison, University B offered at least 26 credit hours or more than $50 \%(26 / 48)$ of the course load in providing Chinese language and cultural content knowledge to future TCFL teachers. It seems that University B has abundant human resources to offer courses on the specific Chinese language content and heavily focused on the subject matter knowledge of their Chinese language graduate teachers.

When interviewed, Dr. Li (pseudonym) from University B mentioned that the TCFL teacher education program was one of the graduate programs in the College of Chinese Linguistics and Culture. As such, the college has many faculty members possess expertise in teaching Chinese linguistics related courses. $\mathrm{He}$ and his colleagues advocated that Chinese teachers should possess solid Chinese language content knowledge in areas such as pinyin, syntax, morphology, etc. so that teachers be able to clear learners' language misconceptions that could occur during a language transfer phenomenon from the first language to the second language. Besides, they also claimed that Chinese teachers must have strong intercultural communication skills to help them to adapt to foreign language classrooms.

In terms of procedural knowledge, based on the number of credit hours, the four Chinese universities offer about one-third of the course loads (30-40\%) on procedural content knowledge. Table 5 included courses that provide future teachers with procedural knowledge to teach the Chinese language to second language learners. In comparison, University $\mathrm{C}$ has more course loads on this domain of knowledge with nearly $42 \%(20 / 48)$ of the total credit hours allocated to prepare teacher candidates' knowledge to teach the Chinese language. The higher percentage was due to the credit hours of the graduate thesis. The graduate thesis for University $C$ was 10 credit hours compared to 2 credit hours for graduate thesis in University A, B, and D.

Table 5

Procedural Knowledge Domain Courses and Total Allocated Credit Hours 


\begin{tabular}{|c|c|c|c|}
\hline University A & University B & University C & University D \\
\hline Language testing & \multirow{2}{*}{$\begin{array}{l}\text { Study of Language } \\
\text { Testing and Teaching } \\
\text { Evaluation }\end{array}$} & Education Psychology & \multirow{2}{*}{$\begin{array}{l}\text { Education } \\
\text { Psychology }\end{array}$} \\
\hline tescaicin & & Modern education & \\
\hline $\begin{array}{l}\text { Acquisition of } \\
\text { network resources }\end{array}$ & Teaching Practice & $\begin{array}{l}\text { technology and Chinese } \\
\text { teaching }\end{array}$ & \multirow{2}{*}{$\begin{array}{l}\text { Classroom } \\
\text { Observation and } \\
\text { Practice }\end{array}$} \\
\hline Technology & \multirow[t]{5}{*}{ Graduation Thesis } & Teaching Practice & \\
\hline $\begin{array}{l}\text { Research on Frontier } \\
\text { Issues in the }\end{array}$ & & Graduation thesis & $\begin{array}{l}\text { Teaching testing } \\
\text { and evaluation }\end{array}$ \\
\hline Humanities & & & $\begin{array}{l}\text { Teaching } \\
\text { Practice }\end{array}$ \\
\hline Teaching Practice & & & \multirow{2}{*}{$\begin{array}{l}\text { Graduation } \\
\text { thesis }\end{array}$} \\
\hline Graduation Thesis & & & \\
\hline 12 Credit hours & 15 Credit hours & 20 Credit hours & 12 Credit hours \\
\hline
\end{tabular}

Table 6

Contextual Knowledge Domain Courses and Total Allocated Credit Hours

\begin{tabular}{|c|c|c|c|}
\hline University A & University B & University C & University D \\
\hline \multirow{6}{*}{$\begin{array}{l}\text { Professional English } \\
\text { Marxism and Social Science } \\
\text { Methodology }\end{array}$} & \multirow{3}{*}{$\begin{array}{l}\text { Professional English } \\
\text { Marxism and Social Science } \\
\text { Methodology }\end{array}$} & $\begin{array}{l}\text { Professional } \\
\text { English }\end{array}$ & $\begin{array}{l}\text { Professional } \\
\text { English }\end{array}$ \\
\hline & & & \\
\hline & & \multirow{4}{*}{$\begin{array}{l}\text { Marxist } \\
\text { political theory }\end{array}$} & $\begin{array}{l}\text { Marxist political } \\
\text { theory }\end{array}$ \\
\hline & Chinese Traditional Arts & & Thai \\
\hline & \multirow[t]{2}{*}{ History of Western Arts } & & Vietnamese \\
\hline & & & $\begin{array}{l}\text { History of } \\
\text { Southeast Asia }\end{array}$ \\
\hline 8 Credit hours & 7 Credit hours & 6 Credit hours & 6 Credit hours \\
\hline
\end{tabular}

Table 6 above included courses that provide future TCFL teachers with contextual knowledge which was crucial to their professional roles. To conform to the national standards, all four Chinese universities have an almost equal number of credit hours in this domain knowledge. However, in terms of weighting percentage, differences are ranging from $13-19 \%$. University A offers nearly $20 \%$ of course loads in 
providing intern teachers with contextual knowledge. Meanwhile, University C has nearly $13 \%$ of the course loads related to contextual knowledge which was minimally for TCFL teachers to perform their teaching tasks. All teacher candidates were required to take some credit hours of professional English to prepare them with English proficiency to communicate with international communities.

To conclude, the curriculum analysis was based on our best knowledge of the master level's TCFL teacher education program curricula in China. Table 7 gives an overview of the composition of the three domains of knowledge across four China universities in comparison with the national curriculum developed by the International Chinese Education Master Program Curriculum Committee Board in 2009.

Table 7

Summary Composition of Domains of Knowledge Base in TCFL Teacher Education Programs in China

\begin{tabular}{|llllll|}
\hline Domains & National & Uni. A & Uni. B & Uni. C & Uni. D \\
Subject Matters & 20 & 22 & 26 & 22 & 24 \\
\hline Procedural & 12 & 12 & 15 & 20 & 12 \\
\hline Contextual & 6 & 8 & 7 & 6 & 6 \\
\hline Total Credit & 38 & 42 & 48 & 48 & 42 \\
\hline
\end{tabular}

\section{Selected TCFL Teacher Education Program Curricula in the US}

Curricular inquiry on four master level's TCFL teacher education programs in the US revealed that the program structures were different from China. Table 8 showed the courses offered by each university to provide subject matter knowledge to TCFL teachers. Ironically, three universities did not offer any Chinese linguistics courses to intern teachers. This could be because the applicants were required to show language proficiency before they will be accepted into the program. The curriculum analysis also implied that US universities have limited faculty resources to offer content-based Chinese language courses in their TCFL teacher education program.

Table 8

Subject Matter Knowledge Domain Courses and Total Credit Hours 


\begin{tabular}{|llll|}
\hline University W & University X & University Y & University Z \\
\hline No course & No course & Topics Chinese linguistics and language & No course \\
\hline 0 Credit hour & 0 Credit hour & 3 Credit hours & 0 Credit hour \\
\hline
\end{tabular}

Table 9

Procedural Knowledge Domain Courses and Total Credit Hours

\begin{tabular}{|c|c|c|c|}
\hline University A & University B & University C & University D \\
\hline $\begin{array}{l}\text { Foreign language } \\
\text { teaching methods } \\
\text { Language concepts } \\
\text { for foreign language } \\
\text { teaching } \\
\text { Second language } \\
\text { acquisition } \\
\text { Teaching a foreign } \\
\text { language with } \\
\text { technology } \\
\text { Experiential module in } \\
\text { foreign language } \\
\text { teaching (Practicum) } \\
\text { Topics in foreign } \\
\text { language teaching } \\
\text { Teaching reading in a } \\
\text { foreign language } \\
\text { Assessment for } \\
\text { foreign language } \\
\text { leaching } \\
\text { Master's Research }\end{array}$ & $\begin{array}{l}\text { Language as a resource: } \\
\text { The functions of language } \\
\text { in teaching and learning } \\
\text { Teaching across the } \\
\text { curriculum } \\
\text { Planned field experience } \\
\text { Core practices in world } \\
\text { language education } \\
\text { Exploring language and } \\
\text { learning } \\
\text { Supervised student teaching } \\
\text { Reflective Seminar }\end{array}$ & $\begin{array}{l}\text { Reading in the } \\
\text { content areas } \\
\text { Second } \\
\text { language } \\
\text { acquisition } \\
\text { and teaching } \\
\text { Professional } \\
\text { field } \\
\text { experience } \\
\text { Capstone } \\
\text { research } \\
\text { project }\end{array}$ & $\begin{array}{l}\text { Planning for K-12 } \\
\text { instruction } \\
\text { Lab in instructional } \\
\text { design } \\
\text { Methods in K-12 foreign } \\
\text { language teaching } \\
\text { Lab in content pedagogy } \\
\text { The middle grades } \\
\text { experience } \\
\text { The secondary school } \\
\text { experiences } \\
\text { The middle-grade } \\
\text { experience } \\
\text { Advanced content } \\
\text { course in the intended } \\
\text { licensure area } \\
\text { Graduate student } \\
\text { teaching internship - } \\
\text { foreign language } \\
\text { education } \\
\text { Assessment in K-12 } \\
\text { foreign language } \\
\text { teaching } \\
\text { Advance methods for } \\
\text { teaching foreign } \\
\text { languages }\end{array}$ \\
\hline 27 Credit hours & 26 Credit hours & 21 Credit hours & 20 Credit hours \\
\hline
\end{tabular}


In contrast, based on the number of credit hours for the domain of procedural knowledge, this indicated that US universities program curricula paid more attention to foreign language teaching methodology. The results revealed that US universities have more faculty resources in conducting foreign language procedural knowledge related courses to TCFL teachers. Most of the courses were run together with other world languages such as Spanish, French, Arabic, Korean, etc. In other words, Chinese intern teachers learn general world language teaching strategies and those strategies were not specific in teaching Chinese as a second. Professional field experience was a core component in this domain of knowledge. Table 9 above listed the courses offered by each university to prepare TCFL teachers with procedural knowledge to perform their role as a foreign language teacher.

Table 10

Contextual Knowledge Domain Courses and Total Credit Hours

\begin{tabular}{|c|c|c|c|}
\hline University W & University $\mathrm{X}$ & University $Y$ & University Z \\
\hline \multirow{4}{*}{$\begin{array}{l}\text { Teaching Culture in } \\
\text { Foreign Language Courses } \\
\text { Foreign Language } \\
\text { Program Development and } \\
\text { Administration }\end{array}$} & Equity and Diversity in & Introduction to & \multirow{2}{*}{$\begin{array}{l}\text { Equity \& Education } \\
\text { Globalization, } \\
\text { Communities and } \\
\text { Schools Students }\end{array}$} \\
\hline & $\begin{array}{l}\text { Teaching of World } \\
\text { Language in } \\
\text { Elementary Schools }\end{array}$ & $\begin{array}{l}\text { History of } \\
\text { education in the } \\
\text { U.S. }\end{array}$ & \\
\hline & $\begin{array}{l}\text { Secondary World } \\
\text { Languages }\end{array}$ & \multirow{2}{*}{$\begin{array}{l}\text { Introduction to } \\
\text { research in } \\
\text { educational study }\end{array}$} & $\begin{array}{l}\text { Principles of Teacher } \\
\text { Leadership }\end{array}$ \\
\hline & $\begin{array}{l}\text { Multi-Tiered Systems } \\
\text { of Support }\end{array}$ & & $\begin{array}{l}\text { Seminar in } \\
\text { Professional } \\
\text { Development }\end{array}$ \\
\hline 6 Credit hours & 12 Credit hours & 9 Credit hours & 14 Credit hours \\
\hline
\end{tabular}

Table 10 included courses that aimed to provide TCFL teachers with specific contextual knowledge. Similarly, based on the number of credit hours, the data indicated that US universities program curricula also pay attention to this domain of knowledge to train all-rounded TCFL teachers. For example, University $\mathrm{Y}$ required intern teachers to know about special education, American history of education, and research knowledge to conduct teacher research in a foreign language classroom. University W and University $Z$ have prepared intern teachers with curriculum development and leadership skills to advance TCFL teachers teaching career. 
To conclude, the curriculum analysis was based on our best knowledge of TCFL teacher education program curricula in the US. The analysis of curricula was also verified by a scholar from a university in Michigan. In comparison, there is some degree of similarities and differences in TCFL teacher education program structures across US universities. Overall, the TCFL program at University $Y$ addresses the three domains of knowledge needed by Chinese teacher candidates. More details, Table 11 gives an overview of the composition of the three domains of knowledge provided by TCFL teacher education programs across four universities in the US.

Table 11

Summary of Domains of Knowledge Provided by TCFL Teacher Education Programs in the US

\begin{tabular}{|lllll|}
\hline Domains & Uni. W & Uni. X & Uni. Y & Uni. Z \\
\hline Subject Matters & 0 & 0 & 3 & 0 \\
\hline Procedural & 27 & 26 & 21 & 20 \\
\hline Contextual & 6 & 12 & 9 & 14 \\
\hline Total Credit & 33 & 38 & 33 & 34 \\
\hline
\end{tabular}

\section{Similarities and differences of TCSLTE program curricula in China and the US}

The curricular inquiry on the master level's TCFL teacher education programs in China and the US revealed that there were similarities and differences in the program structures and courses offered. These differences have a great impact on the Chinese teacher's knowledge base. Overall, TCSLTE programs in China required more credit hours to obtain a master's degree compared to TCSLTE programs in the US. In terms of subject matters knowledge, TCFLTE programs in China have allocated nearly $50 \%$ of total program credit hours in providing their teacher candidates with solid content knowledge on Chinese linguistic and cultural knowledge. In contrast, the majority of US universities have not offered any Chinese linguistics related courses to their teacher candidates. Next, with regards to procedural knowledge, TCFLTE programs in the US have offered more credit hours $(80 \%)$ on teaching world language pedagogy in general but is not specific in teaching Chinese as a foreign language. There were pedagogy courses related to specific school levels too such as Teaching World Language in Elementary Schools and Teaching Middle Grades. In contrast, only about $20-25 \%$ of the total course loads were allocated to procedural knowledge-based courses in China's TCFLTE programs.

Analysis data also indicated that TCFLTE programs in both China and the US have provided necessary contextual knowledge for Chinese teachers to perform daily teaching role. For example, in the US, contextual knowledge such as how to teach special needs children, school leadership development, equity issues, and American education Acts and policies were provided to teacher candidates.

Comparatively, TCFLTE programs in China emphasize on the political knowledge about Marxism and the 
English language proficiency of their teacher candidates. Based on the interview data with educators in China, all teacher candidates in China must learn and embrace the country's socialism philosophy.

Teacher candidates were mandatory to pass the English language proficiency examinations to prepare them to teach in foreign language classrooms. Table 12 showed a comparison of the program structures of TCFLTE programs in China and the US.

Table 12

Comparison of TCFLTE Program Structures between China and the US

\begin{tabular}{|c|c|c|c|c|c|c|c|c|}
\hline \multirow[t]{2}{*}{ Domains } & \multicolumn{4}{|l|}{ China } & \multicolumn{4}{|c|}{ United States } \\
\hline & Uni. A & Uni. B & Uni. C & Uni. D & Uni. W & Uni. X & Uni. Y & Uni. Z \\
\hline Subject Matters & 22 & 26 & 22 & 24 & 0 & 0 & 3 & 0 \\
\hline Procedural & 12 & 15 & 20 & 12 & 27 & 26 & 21 & 20 \\
\hline Contextual & 8 & 7 & 6 & 6 & 6 & 12 & 9 & 14 \\
\hline Total Credit & 42 & 48 & 48 & 42 & 33 & 38 & 33 & 34 \\
\hline
\end{tabular}

\section{Domains of knowledge in the TCSLTE program curricula in China and the US}

Interview participants from China believed that TCFL teachers should be trained using a dual-focus model, i.e., Chinese language subject matter knowledge plus procedural knowledge. As such, teacher candidates from all four Chinese TCSL teacher education programs are required to complete more than $50 \%$ of Chinese language and linguistics related courses. In terms of Chinese cultural knowledge, Chinese cultural courses such as calligraphy, Chinese painting, Tai Chi, Chinese paper cutting, Chinese opera, tea ceremony, Chinese art, and craft, etc., courses were also offered to strengthen teacher candidates' qualification. In addition to subject matter knowledge, teacher candidates usually place at university's Chinese language centers, private language centers, international schools, or community-based language centers for one semester- long teaching practices ( 6 credit). Practicum usually scheduled in the final semester of the programs. Through teaching practice platforms, knowledge, or pedagogical skills about teaching Chinese as a foreign language will be practiced or reinforced. They believed that teaching Chinses as a foreign language teaching strategy should be integrated and implemented during the teaching practices.

According to a faculty from Hangzhou, currently, about 50 training centers have been set up in the Zhejiang province to accommodate the needs for professional field placement of the TCFL programs 
teacher candidates. Every new teacher must complete at least 120 field experience hours of training before beginning his or her teaching position. Additionally, through collaboration with Hanban, many TCFL programs teacher candidates have been hired to work as volunteer teachers for the Confucius Institutes worldwide. As such, Chinese teacher educators claimed that TCFL master programs teacher candidates in China were selected through a competitive process. If the candidates' bachelor's degree was not major in TCFL, they have to register for more content core courses. Chinese educators advocated that TCFL program courses should be conducted through a discussion of the case study. They also believed that seminars, essay writing, and final examination will strengthen the domains of knowledge needed to serve their role as a foreign language teacher. In terms of contextual knowledge, a teacher educator from Yunnan explained that the TCFLTE program in his university offered languages used by South East Asia communities. Considering that majority of the graduates from TCFLTE programs will be placed at Confucius Institutes in South East Asia countries, teacher candidates in this program require to learn at least two credit hours of Thai/Cambodia/Vietnam language before graduation. As China adopts Marxism ideology, Marxist Political Theory ( 2 credit) is a compulsory course for all teacher candidates in the TCFLTE programs.

Based on the curriculum analysis of TCFLTE programs in the US, interview participants from the US recommended that TCFLTE programs in the US should include more courses on Chinese language and culture. The assertation was based on the fact that the Chinese language is character-based and hence, procedural knowledge in teaching Chinese should be viewed as different from teaching alphabetical language such as Spain, German, etc. A teacher educator from University Y mentioned that the second language acquisition course was specifically offered to Chinese intern teachers in her university. Ironically, none of the TCFLTE programs in the US offered intercultural communication-related courses. To prepare Chinese teachers to work in the K-12 classrooms in the US, knowledge about diversity and inclusion is strongly recommended to be included in the TCFLTE programs.

\section{Discussion}

In this comparative study, three research questions were formulated to explore what domain of knowledge integrated into the master level's TCFL program curricula in China and the US. The study also compared the similarities and differences of TCSLTE programs curricula in both countries and what knowledge base should be included in the programs. Findings of this comparative study were in accordance with some previous studies regarding the language teacher knowledge base (Day, 1993; Faez, 2011; Freeman \& Johnson, 1998; Richards, 1998; Tedick, 2009; Zeichner, 2006). First, curriculum analysis indicated the TCFL teachers' knowledge base can be categorized into three domains, i.e., subject matter knowledge, procedural knowledge, and contextual knowledge. Taken as a whole, both countries focus on the different domains of knowledge with China emphasizes subject matter knowledge and the US focuses more on procedural knowledge. Hence, Chinese teachers who were graduated from TCFLTE programs in China and the US possess different knowledge base. 
Second, due to sociocultural contextual factors, TCSLTE programs in China and the US placed different emphasis on the domain of knowledge. This measure could further restrict the employment of Mandarin Chinese teachers in the international market. For instance, Chinese teachers who were trained in China may have difficulty in adapting their teaching in the US foreign language classrooms. Inevitably, they lack training in the practical applications of foreign/second language teaching techniques, thus making it difficult for them to meet international teaching standards (Cheng, 2015, p. 303; Crandall, 2000, p.43). Furthermore, a great percentage of Chinese teachers who graduated from China universities were not ready to meet the change from domestic teaching to teaching Chinese outside China. These teachers need to be re-trained according to the new requirements if recruited to teach in the US (Cheng, 2015, p. 303). In contrast, Chinese teachers who graduated from the US's TCFL programs likely to lack subject matters knowledge to serve their teaching role in China. It is evidenced that the US's TCFL programs only recruit Chinese native speakers or near-native speakers. The linkage between native-speaking proficiency and professional competence is also often misconstrued (Crandall, 2000, p.43). The literature reviewed indicated that the ability to speak a language was not equivalent to the ability to use second language teaching pedagogies (Lafayette, 1993; Orton, 2011; Senchuk, 1984). It is also true that content knowledge does not translate automatically into pedagogical content knowledge.

Third, the current TCFL curricula in China and the US were imperfect. In China, TCFL teacher education program curricula emphasize on subject matter knowledge. Graduates from these programs were found do not possess sufficient pedagogical knowledge and experience in TCFL/TCSL (Cheng, 2015, p. 303). Also, intern teachers were placed at university or college level language classes for professional field experience. As such, Chinese teachers faced challenges when teaching in foreign K-12 schools. Therefore, to meet the increasing international demand for Chinese language teachers worldwide, China should improve its current TCFL program curriculum in preparing more qualified teachers to teach outside of China. Meanwhile, in the US, TCFL teacher education curricula should include some content of Chinese linguistics. This will ensure that Chinese teachers develop a command of the Chinese language and culture. Besides, the US's TCFL program curricula should develop intern teachers with a broader understanding of the world to increase their cross-cultural consciousness (Cheng, 2015, p. 303).

Lastly, curricula analysis indicated that the master level's TCFLTE programs in China conform to national curriculum standards developed by the International Chinese Education Master Program Curriculum Committee Board. Even though all universities have different program structures, curricula were emphasized in offering Chinese linguistics and language content courses. The curriculum was structured in a way that could be due to the national teacher certification examination format. Upon graduation from the TCFLTE programs, graduates are required to register and obtain a teaching certificate within 60 days of completing their probation periods. The certification examination consists of two sections: the written examination and the interview. The written examination assesses graduates' subject matter knowledge while the interview section assesses basic teaching skills, assessment, and teacher dispositions (OCED, 2016, p.19). In contrast, all TCFL program curriculum in the US has to meet CAEP Standards and respective states' teacher education program standards. For example, Chinese intern teachers in Michigan have to adhere to In-TASC Standards. Concerning certification, there was no 
standardized testing for teacher certification in the US. For example, in Michigan, upon graduation, teacher candidates have to pass Michigan Teacher Teaching Certificate (MTT) written test organized by Pearson, obtain a speaking test score by ACTFL along with a Child/Adult first-aid certificate and a background check result to apply for the Mandarin Chinese teaching certificate.

\section{Conclusions}

This study aimed to conduct a comparative curricular inquiry of TCFL teacher education programs in China and the US. The primary goal of this study was to investigate Chinese teachers' knowledge base in two different sociocultural contexts. To conclude, the curriculum analysis was based on our best knowledge of the TCFL teacher education program curricula in China and the US. The curricular inquiry revealed some interesting similarities and differences among and between TCFLTE programs in China and the US. Both countries focus on different domains of knowledge. China emphasis subject matters knowledge and the US focuses more on procedural knowledge. As such, Chinese teachers who were graduated from TCFLTE programs in China and the US possess different knowledge base. Herein lies a critical connotation, Mandarin Chinese teachers' knowledge base is context-bound.

This study suggested that the TCFL teacher education program curricula in China should modify to focus more on the processes of Chinese second language teaching. Particularly at the graduate level, the pedagogical knowledge of teaching Chinese as a foreign language should be strengthened to improve the employability of Chinese graduate teachers outside of China. On the other hand, the findings asserted that the US's TCFL teacher education curricula should focus more on the Chinese language subject matter knowledge so that graduates possess in-depth content knowledge to handle students' misconceptions in second language acquisition. Taken together, this comparative study contributes to scholarly information about Mandarin Chinese teachers' knowledge base and enhance our understanding of this field of study. There are several aspects of this comparative study that limit our findings. First, the findings have limited generalizability due to bias in the selection of participants. The TCFL programs in China were convenience samples as they were our university's partners in China. Teacher educators who volunteered to participate in the interviews may not be representative of curriculum developers. Second, the number of participants for the interview was small and this limits the generalizability of the findings in this study too. The limitations of this study point towards aspects to be addressed in the future. Future research is recommended to use a larger sample size for the curricula inquiry and interview participants to reduce the selection bias for the sample. Third, this curriculum inquiry was conducted on graduatelevel TCFLTE programs only, thus the findings may not relevant to the undergraduate level's TCFLTE program outcomes. Additional research needs to address to most limiting factors of this study. Finally, it is worthwhile to expand the scope of the investigation by reviewing the curriculum of some undergraduate TCFL programs in China and the US. This will provide a more holistic picture of Mandarin Chinese teachers' knowledge base as a whole.

\section{List Of Abbreviations}




\begin{tabular}{|ll|}
\hline ACTFL & American Council for Teaching Foreign Language \\
\hline CAEP & Accreditation of Educator Preparation \\
\hline MA & Master of Arts \\
\hline MATCSL & MA in teaching Chinese as a Second Language \\
\hline MTCSOL & Master of Teaching Chinese to Speakers of Other Languages \\
\hline PCK & Pedagogical Content Knowledge \\
\hline SLTE & Second Language Teacher Education \\
\hline TCFL & Teaching Chinese as a Foreign Language \\
\hline TCFLTE & Teaching Chinese as a Foreign Language Teacher Education \\
\hline TCSLTE & Teaching Chinese as a Second Language Teacher Education \\
\hline US & United States \\
\hline
\end{tabular}

\section{Declarations}

\section{Availability of data and material}

The data will not be shared as requested by the interview participants and their respective university or programs.

\section{Funding}

The research is supported by Western Michigan University, College of Education and Human Development International Collaborative Research Grant, Timothy Light Chinese Center Mini Grant and International Education Faculty Development Fund.

\section{Authors' contributions}

MML participated in the sequence alignment and designation of the research. She also participated in the collection and processing of data and drafted the manuscript. LL participated in translating interview questions and the interview data from Chinese to English, and performed the document analysis. All authors read and approved the final manuscript.

\section{Competing interests}

The authors declare that they have no competing financial interests.

\section{Author details}


${ }^{1}$ College of Education and Human Development, Western Michigan University, 1903, W. Michigan Ave, Kalamazoo, MI 49008-5276, USA.

${ }^{2}$ College of Education and Human Development, Western Michigan University, 1903, W. Michigan Ave, Kalamazoo, MI 49008-5276, USA. liu.liu@wmich.edu

\section{Acknowledgements}

Not applicable

\section{References}

1. Barahona, M. (2014). Pre-service teachers' beliefs in the activity of learning to teach English in the Chilean context. Cultural Historical Psychology, 10(2), 116-122.

2. Borg, S. (2003). Teacher cognition in language teaching: A review of research on what teachers think, know, believe, and do. Language Teaching, 36, 81-109. doi:10.1017/S0261444803001903

3. CAEP. (2015). Program Standards for the Preparation of Foreign Language Teachers. Retrieved from https://www.actfl.org/sites/default/files/CAEP/ACTFLCAEPStandards2013_v2015.pdf

4. Cheng A. M. (2015). Teaching Chinese in the global context: Challenges and strategies European Review, 23(2), 297-308. doi:10.1017/S1062798714000672

5. Crandall, J. (2000). Language teacher education. Annual Review of Applied Linguistics, 20, 34-55.

6. Darling-Hammond, L. (2006). Powerful teacher education: lessons from exemplary program. San Francisco: Jossey-Bass.

7. Day, R. R. (1993). Models and the knowledge base of second language teacher education. University of Hawaii's Working Papers in ESL, 11(2), 1-13.

8. Dooley, C. M., Dangel, J. R., \& Farran, L. K. (2011). Current Issues in Teacher Education: 2006<2009. Action in Teacher Education, 33(3), 298-313. doi:10.1080/01626620.2011.592125

9. Ellis, N., \& Loughland, T. (2016). The challenges of practitioner research: A comparative study of Singapore and NSW. Australian Journal of Teacher Education, 41(2), 112-136.

10. Faez, F. (2011). Points of departure: Developing the knowledge base of ESL and FSL teachers for K12 programs in Canada. The Canadian Journal of Applied Linguistics, 14(1), 48-82.

11. Freeman, D. (1989). Teacher training, development, and decision making: A model of teaching and related strategies for language teacher education. TESOL Quarterly, 23(1), 27-45.

12. Freeman, D., \& Johnson, K. E. (1998). Reconceptualizing the knowledge-base of language teacher education. TESOL Quarterly, 32(3), 397-417. doi:10.2307/3588114

13. Golombek, P. R. (1998). A Case study of second language teachers' personal practical knowledge. TESOL Quarterly, 32, 447-464.

14. Grant, C. A., \& Gillette, M. (2006). A candid talk to teacher educators about effectively preparing teachers who can teach everyone's children. Journal of Teacher Education, 57(3), 292-299. 
doi:10.1177/0022487105285894

15. Hüttner, J. I., Reichl, S., \& Schiftner, B. (2012). Introduction. In J. I. Hüttner, B. Mehlmauer-Larcher, S. Reichl \& B. Schiftner (Eds.), Theory and practice in EFL teacher education: bridging the gap (pp. viiixix). Bristol, UK: Multilingual Matters.

16. Hanban. (2012). Standards for Teachers of Chinese to Speakers of Other Languages. Beijing:Foreign Language Teaching and Research Press.

17. Intrator, S. M. (2006). Beginning teachers and the emotional drama of the classroom. Journal of Teacher Education, 57(3), 232-239. https://doi.org/10.1177/0022487105285890

18. Johnson, K. E. (1999). Understanding language teaching: Reasoning in action. Boston: Heinle and Heinle.

19. Johnston, B., \& Goettsch, K. (2000). In search of the knowledge base of language teaching: Explanations by experienced teachers. The Canadian Modern Language Review, 56(3), 437-468.

20. Ke, C. R., \& Li, Y. H. (2011). Chinese as a foreign language in the US. Journal of Chinese Linguistics, 39(1), 177-238.

21. Kumaravadivelu, B. (2012). Language teacher education for a global society: a modular model for knowing, analyzing, recognizing, doing, and seeing. New York: Routledge.

22. Lafayette, R. C. (1993). Subject-matter content: What every foreign language teacher needs to know. In G. Guntermann (Ed.), Developing language teachers for a changing world (pp. 125-157). Lincolnwood, IL: National Textbook.

23. Liao, W., Yuan, R., \& Zhang, H. (2017). Chinese Language Teachers' Challenges in Teaching in U.S. Public Schools: A Dynamic Portrayal. Asia-Pacific Educational Research, 26(6), 369-381. doi:10.1007/s40299-017-0356-z

24. Malderez, A., \& Wedell, M. (2007). Teaching teachers: Processes and practices. London: Continuum.

25. Mattsson, M., Eilertsen, T. V., \& Rorrison, D. (2011). A Practicum turns in teacher education. Rotterdam: Sense.

26. Nguyen, M. (2013). The curriculum for English language teacher education in Australian and Vietnamese universities. Australian Journal of Teacher Education, 38(11), 33-53.

27. OECD. (2016). Education in China: A snapshot. Retrieved from http://www.oecd.org/china/Education-in-China-a-snapshot.pdf

28. Orton, J. (2011). Educating Chinese language teachers - Some fundamentals. In L. Tsung \& K. 29. Cruickshank (Eds.), Teaching and learning Chinese in global contexts (pp. 151-164). London: Continuum.

30. Richards, J. C. (1998). Second language teacher education today. RELC, 39(158), 158-177.

31. Roberts, J. (1998). Language teacher education. London: Arnold.

32. Senchuk, P. (1984). The polymorphous character of teaching. Educational Theory, 34, 183-192.

33. Shulman, L. (1987). Knowledge and teaching: Foundations of the new reform. Harvard Educational Review, 57(1), 1-23. 
34. Tedick, D. J. (2009). K-12 language teacher preparation programs: Problems and possibilities. The Modern Language Journal, 93(2), 263-267.

35. Wang, D., Moloney, R., \& Li, Z. (2013). Towards internationalising the curriculum: A case study of Chinese language teacher education programs in China and Australia. Australian Journal of Teacher Education, 38(9). doi:10.14221/ajte.12013v14238n14229.14228

36. Wang, H., \& Tian, K. (2013). Basic issues in teaching foreign language in the US: A case study of cross-cultural communications. Journal of Higher Education Theory and Practice, 13(3/4), 143-148.

37. Western Michigan University (2020, June 18). M.A. Teaching Chinese as a second language: Additional program requirement. Retrieved from https://wmich.edu/grad/admissions/single.php? $\mathrm{id}=180$

38. $\mathrm{Xu}, \mathrm{H}$. (2012). Challenges native Chinese teachers face in teaching Chinese as a foreign language to non-native Chinese students in U.S. classrooms (Master's Thesis, University of Nebraska). Retrieved from http://citeseerx.ist.psu.edu/viewdoc/download?doi=10.1.1.461.1046\&rep=rep1\&type=pdf

39. Zeichner, K. (2006). Reflections of a university-based teacher educator on the future of college and university-based teacher education. Journal of Teacher Education, 57(3), 326-340. https://doi.org/10.1177/0022487105285893

40. Zhu, X. D., \& Han, X. (2006). Reconstruction of the teacher education system in China. International Education Journal, 7(1), 66-73. 